\title{
Influence of low level laser therapy versus pulsed electromagnetic field on diabetic peripheral neuropathy
}

Rabab A. Mohamed ${ }^{1 *}$, Ghada A. Abdallah², Heba A. Abdeen ${ }^{3}$ and Ayman A. Nassif ${ }^{4}$

*Correspondence: rabab_ali1978@hotmail.com

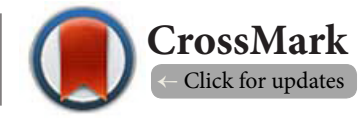

\footnotetext{
1,2Basic Science Department, Faculty of Physical Therapy, Cairo University, Giza, Egypt.

${ }^{3}$ Lecturer of Physical Therapy for Cardiovascular/ Respiratory Disorder and Geriatrics, Faculty of Physical Therapy, Cairo University, Egypt. ${ }^{4}$ Physical Therapy for Neuromuscular disorders and its surgery Department, Faculty of Physical Therapy, Cairo University, Giza, Egypt.
}

\begin{abstract}
Background: Peripheral neuropathy is a common complaint of diabetes, leading to pain and reduced motor nerve conduction velocity. Clinical symptoms of peripheral neuropathy are present in approximately $25 \%$ of diabetic individuals, while nearly all diabetics have a reduction of nerve conduction velocity.

Purpose: This study aimed to evaluate and compare the effect of low-level laser therapy (LLLT) versus pulsed electromagnetic field (PEMF) on pain intensity and motor nerve conduction velocity (MNCV) in patients with diabetic neuropathy.

Methods: Thirty patientswith type II diabetes suffering from diabetic peripheral neuropathy, participated in this study for 4 weeks (3 sessions/week), and were chosen randomly from the diabetes and endocrine institution.Patients were randomized equally into two groups: Group A (LLLT group): received LLLT for lower extremities for 12 sessions at a frequency of 3 sessions/week. Group B (PEMF): received pulsed electromagnetic field for 12 sessions at a frequency of 3 sessions/week.

$\underline{\text { Results: }}$ At the end of the study; there was non-significant difference between two groups post-study in pain level where P-values was (0.606). There were no significant differences between two groups in amplitude, distal latency and MNCV of RT side post-study, where P-values were (0.082), (0.911) and (0.342) respectively. There were no significant differences between two groups in amplitude, distal latency and MNCV of LT side post-study, where P-values were (0.265), (0.550) and (0.334) respectively.

Conclusions: The study findings indicate that both LLLT andPEMF could be effective therapeutic modalities in the treatment of painful diabetic neuropathy in that they are able to modify pain, and some electrophysiological parameters of peripheral nerve function.
\end{abstract}

Keywords: Low-level laser therapy, Pulsed electromagnetic field, Neuropathy, Diabetes

\section{Introduction}

One of the most common complications of diabetes mellitus is painful diabetic neuropathy (PDN). Within 10 to 15 years of diabetes approximately $50 \%$ of patients will develop PDN [1]. In neuropathy, there is a progressive degeneration of the peripheral nerves in the lower limbs especially, that leads to sensory and motor deficits [2]. Diabetic peripheral neuropathy (DPN) is a frequent complication of diabetes that affects up to $50 \%$ diabetic patients in the United States $[3,4]$. It is a major cause of morbidity and increased mortality, and is associated with duration of diabetes, hyperlipidemia, and poor glycemic control [4]. Diabetic polyneuropathy affects both large and small sensory afferent nerve fibers. Conduction velocities in motor nerves reduced in patients with diabetic neuropathy [5]. Studies showed that large fiber involvement (group la) polyneuropathy and abnormal muscle spindle innervations can lead to lose lower extremities proprioception as ankle position sense, decreased tactile sensitivity and ankle vibratory sense that are responsible for maintaining postural stability and walking [6]. Diabetic polyneuropathy also affected small 
Mohamed et al. Physical Therapy and Rehabilitation 2017,

nerve fibers that responsible for pain and temperature sense causing decreased sensory nerve conduction velocity [7].

In many patients with diabetic neuropathy, pain will develop as a symptom, affecting up to $30 \%$ of the diabetic population; symptoms are localized to the lower extremities, primarily the soles and toes [8]. In addition to discomfort, all areas of patients' lives including sleep, mood, mobility, ability to work, interpersonal relationships, overall self-worth, and independence, are affected [9].

Current therapy for DPN is purely symptomatic, aiming to relieve the pain through the administration of various analgesic drugs. These drugs are effective, but no more than $40-60 \%$ of patients show adequate symptomatic relief. Moreover, these drugs are frequently associated with central nervous system side effects and do not slow the progression of the underlying neuropathy [10]. The efficacy of most conservative treatment options for painful diabetic neuropathy is still little known. Among the different options for treatment, low-level laser therapy (LLLT) may have the potential to induce a biostimulational effect on the nervous system $[11,12]$. Because the typical aetiology of peripheral neuropathic pain starts with injury to a peripheral nerve, the great majority of research into the treatment of neuropathic pain is focused predominantly on the nerves themselves. Several clinical and experimental research studies on peripheral nerve injuries used LLLT because it promotes microcirculation in the irradiated area; increases nerve functional activity increases the rate of axon growth and myelination and improves regeneration of the injured nerve $[13,14]$. In addition, low-power laser has also been employed for the treatment of other diabetic complications, such as foot ulcers [15], diabetic microangiopathy $[16,17]$ and wound healing $[18]$. Also, it has been shown that regular exercise with or without dietary intervention and/ or oral blood glucose-lowering medication has benefits in patients with Type 2 diabetes $[19,20]$.

One of the approaches which is currently of clinical interest includes pulsed electromagnetic fields (PEMF), which have analgesic, neurostimulatory, trophic, and vasoactive actions [21]. PEMF treatment has the potential to modulate neuropathic pain and nerve impulse. It may be due to decrease in endoneural hypoxia, perineural edema, ischemia of peripheral nerves, and improved microcirculation that leads to positive changes after treatment sessions [22].

The problem of nerve damage in diabetes is one of the most neurological and metabolic diseases, which is still over looked by scientists [23]. The nerve damage of polyneuropathy lies in a gray zone; it is equally attributed to both mild segmental demyelination and axonal degeneration [24].

To our knowledge, no study has yet compared magnetic field therapy (which has limited research supporting its use), andLLLT (which is among the most common treatments fordiabetic neuropathy), in patients with diabetic neuropathy. Thus, our aim was to investigate which modality gives better results in treatingdiabetic neuropathy.

\section{Material and methods Subjects}

A total of 30 patients withtype II diabetes suffering from diabetic peripheral neuropathy, participated in this study for 4 weeks ( 3 sessions / week), and were chosen randomly from the diabetes and endocrine institutionfor this study. Eligible patients included ( 20 women and 10 men), ranging in age from 40 to 60 years with a mean of $(47.5 \pm 2.38)$ years. The patients had longstanding type 2 diabetes associated with painful peripheral neuropathic symptoms for more than 6 monthsinvolving both lower extremities and complained of burning pain with paresthesia in both legs. Neurological examination of the patients revealed sensory abnormalities in both lower extremities. Patients were excluded from the study if theyhad unstable glycemic control and/or medical conditions that would confound assessment of neuropathy such as malignancy, active/untreated thyroid disease, peripheral vascular diseases (PVD), vascular insufficiency, significant renal or hepatic disease, pregnancy and nerve damage as a result of prior reconstructive or replacement knee surgery, back surgery, spinal stenosis, spinal compression or radiculopathy.Patients were randomly assigned equally into two groups each group included 15 patients. Group A (LLLT group): received LLLT for lower extremities for 12 sessions at a frequency of 3 sessions/ week. Group B (PEMF group): receivedPEMFfor 12 sessions at a frequency of 3 sessions/ week.The randomization was done by a colleague independent and blind to the studywho took a sealed opaque envelope from a box following a numerical sequence; within which the group description was randomly placed within them.

\section{Instrumentation \\ Assessment Instrument \\ Visual Analog Scale}

It was used to measure the intensity of pain pre and post treatment. It is a vertical or horizontal line graduated by different levels of pain starting from ( 0 - no pain) till (10- worst pain). The VAS is a reliable and valid tool for the quantification of perceived pain [25].

\section{Electromyography Device for Nerve Conduction Studies} The measurement ofperoneal motor conduction velocity ( $P$ $\mathrm{MCV}$ ), amplitude and distal latencywas measured by using Computerized Electromyography TonniesNeuroscreenPlus Version 1.59 (1998; Erich Jaeger GmbH, Hoechberg, Germany).

\section{Treatment Instrument \\ Laser Scanner device}

Italy ASA Co., Bravo Style of laser used in this study. It produces combined irradiation of He-Ne and infrared laser. The device emits both helium- neon and infra-red laser in a mixed light. He- Ne wave length was $632.8 \mathrm{~nm}$, continuous. Infra-red wave length was from 780-905 nm, pulsed this device discharges a uniform irradiation of the relatively large areas in a carefully 
controlled and prescribed manner. Infrared Laser applied on both feet for twenty minutes using frequency of $150 \mathrm{hz}$ wave length of $905 \mathrm{~nm}$ and an average power of $0-60 \mathrm{w}$, with energy density of 3.6 joules $/ \mathrm{cm}^{2}$.

\section{Pulsed electromagnetic field}

Using ASA magnetic field for magneto therapy, its model is Automatic PMT Quattro PRO.The appliance must be connected to electrical mains supplying $230 \vee 10 \%$ at a frequency of 50 or $60 \mathrm{~Hz}$ with earth connection. The frequency of output magnetic impulses ranged from 0.5 up to $100 \mathrm{~Hz}$, and the intensity was displayed in percentage ranged from $5 \%$ to $100 \%$ of the maximum layout of the solenoid used. The intensity and spatial layout of the generated magnetic field of the appliance varied according to the type solenoid used whether for trunk, limb or Transcranial.

\section{Evaluative Procedure \\ Pain Assessment}

The level of pain was assessed by using VAS, the patient was asked to determine the level of his/her pain on $10 \mathrm{~cm}$ scale as $(0=$ no pain) and ( $10=$ worst pain) by drawing a line corresponding to the intensity of pain. Assessment of pain was done before starting the program of treatment and after compliance of all treatment sessions.

\section{Electrophysiological Assessment}

Conventional NCSs were administered using a standard testing protocol. Studies included testing of bilateral peroneal MCV, amplitude and distal latency. All measurements were done under standard room temperature of $25 \mathrm{C}$. The skin temperature of the leg was maintained at 37C. Procedure of nerve conduction velocity measurement. The patients were positioned supine. An active electrodewas placed over the midpoint of the extensor digitorumbrevis muscle on the dorsum of the foot. Reference electrode was placed slightly distal to the fifthmetatarsophalangeal joint. Ground electrode placement was over the dorsum of the foot. Stimulation point 1 (S1): the cathode was placed $10 \mathrm{~cm}$ proximal to the active electrode, slightly lateral to the tibialis anterior tendon. Stimulation point 2 (S2):the cathode was slightly posterior and inferior to the fibular head. The anode was proximal. Pulse duration of $0.2 \mathrm{~ms}$ at the rate of $1 / \mathrm{s}$ at supramaximal intensity was used for conduction studies. The distance between S1 and S2 was measured by tap measurement and entered into the computerized electromyography device. The device automatically calculates the motor conduction velocity [26].

\section{Treatment Procedure \\ Low Intensity Laser Therapy (LLLT)}

Patient was placed in supine lying, fully relaxed and supported position .the area of laser application on the leg and foot was washed by alcohol. The laser scanner was applied perpendicular on the area of laser application. The laser beam was adjusted to cover the area of application in width and length from the malleoli till tip of the big toes. Infrared Laser applied on both feet for twenty minutes using frequency of $150 \mathrm{hz}$ wave length of $905 \mathrm{~nm}$ and an average power of 0-60w, with energy density of 3.6 joules $/ \mathrm{cm}^{2}$ [27].

\section{Pulsed Electromagnetic Fields}

Pulsed electromagnetic fields (ASA Easy terza series; Italy) was used in the treatment of group A only. Each patient was placed in a comfortable relaxed position (supine position). The appliance was connected to electrical mains supplying $230 \mathrm{~V}$. The solenoid was adjusted to be over the lower limb, with frequency of $50 \mathrm{~Hz}$ and intensity of $20 \mathrm{G}$ for $20 \mathrm{~min}$. Treatment was conducted for 4 weeks, three times per week, day after day [28].

\section{Statistical Analysis}

Statistical analysis was performed using SPSS software (version 16.0). Data were expressed as mean \pm standard deviation (SD). Mean changes within groups (pre and post-study) were analyzed using Paired T-test while mean changes between groups (pre and post-study) were analyzed using unpaired T-test to test hypothesis between groups. The level of significance was set at $p<0.05$.

\section{Results}

This study was concerned with comparison between the effect of PEMF versus LLLT on pain intensity and motor nerve conduction velocity (MNCV) in patients with diabetic neuropathy. Thirty subjects were assigned randomly into two equal groups.

Group (A): Fifteen subjects received LLLT for lower extremities. The data in Table 1 represented, their mean age $(47.5 \pm 2.38)$ years, weight $(74.2 \pm 2.7) \mathrm{kg}$ and height $(162.1 \pm 2.08) \mathrm{cm}$.

Table 1. General Characteristics of subjects in both groups.

\begin{tabular}{llll}
\hline General characteristics & Age $($ yrs $)$ & Weight $(\mathbf{k g})$ & Height $(\mathbf{c m})$ \\
\hline Group A Mean \pm SD & $47.5 \pm 2.38$ & $74.2 \pm 2.7$ & $162.1 \pm 2.08$ \\
Group B Mean \pm SD & $46.33 \pm 1.29$ & $76 \pm 2.5$ & $161.5 \pm 1.6$ \\
t-value & 1.713 & -1.88 & 0.894 \\
P-value & 0.098 & 0.071 & 0.379 \\
\hline
\end{tabular}

Group (B): Fifteen subjects receivedPEMF. The data in Table 1 represented, their mean age $(46.33 \pm 1.29)$ years, weight $(76 \pm 2.5) \mathrm{kg}$ and height $(161.5 \pm 1.6) \mathrm{cm}$. There was no significant difference between two groups in their mean age, weight and height, where P-values were (0.098), (0.071) and (0.379) respectively.

\section{Pre study means values within both groups}

As shown in Table 2, the mean values and SD of pain for groups ( $A$ and $B$ ) before the study were $(7.8 \pm 0.86),(7.66 \pm 1.17)$ 
Mohamed et al. Physical Therapy and Rehabilitation 2017,

http://www.hoajonline.com/journals/pdf/2055-2386-4-17.pdf

doi: $10.7243 / 2055-2386-4-17$

Table 2. Pre-study mean values of measured variables for both groups.

\begin{tabular}{llllll}
\hline \multicolumn{7}{c}{ Pre-study } \\
\hline & & $\begin{array}{l}\text { Group A } \\
\text { Mean } \pm \text { SD }\end{array}$ & $\begin{array}{l}\text { Group B } \\
\text { Mean } \pm \text { SD }\end{array}$ & t-value & p-value \\
\hline Pain level & & $7.8 \pm 0.86$ & $7.66 \pm 1.17$ & 0.354 & 0.726 \\
\hline Amplitude & RT & $1.32 \pm 0.278$ & $1.43 \pm 0.286$ & -1.09 & 0.281 \\
& LT & $1.11 \pm 0.44$ & $1.35 \pm 0.48$ & -1.39 & 0.174 \\
\hline Distal latency & RT & $6.08 \pm 0.598$ & $6.05 \pm 0.68$ & 0.113 & 0.911 \\
& LT & $5.87 \pm 0.74$ & $5.66 \pm 0.64$ & 0.815 & 0.422 \\
\hline MNCV & RT & $40.68 \pm 2.83$ & $41.07 \pm 2.79$ & -0.378 & 0.708 \\
& LT & $38.5 \pm 4.82$ & $39.11 \pm 3.52$ & -0.371 & 0.713 \\
\hline
\end{tabular}

respectively. The mean values and SD of amplitude of RT side for groups (A and B) before the study were $(1.32 \pm 0.278)$ and $(1.43 \pm 0.286)$ respectively, of LT side were $(1.11 \pm 0.44)$ and $(1.35 \pm 0.48)$ respectively. The mean values and SD of distal latency of RT side for groups ( $A$ and $B$ ) before the study were $(6.08 \pm 0.598)$ and $(6.05 \pm 0.68)$ respectively, of LT side were $(5.87 \pm 0.74)$ and $(5.66 \pm 0.64)$ respectively. The mean values and SD of MNCV of RT side for groups ( $A$ and $B$ ) before the study were $(40.68 \pm 2.83)$ and $(41.07 \pm 2.79)$ respectively, of $L T$ side were (38.5 \pm 4.82$)$ and $(39.11 \pm 3.52)$ respectively. There was no significant difference between two groups pre-study in pain level where $P$-values was $(0.726)$. There were no significant differences between two groups in amplitude, distal latency and MNCV of RT side pre-study, where P-values were (0.281), $(0.911)$ and $(0.708)$ respectively. There were no significant differences between two groups in amplitude, distal latency and MNCV of LT side pre-study, where P-values were (0.174), $(0.422)$ and $(0.713)$ respectively.

\section{Post study mean values within both groups}

As shown in Table 3, the mean values and SD of pain for groups (A and $B$ ) after the study were $(2 \pm 0.53),(2.1 \pm 0.833)$ respectively. The mean values and SD of amplitude of RT side for groups ( $A$ and $B)$ after the study were $(1.85 \pm 0.388)$ and $(2.1 \pm 0.383)$ respectively, of LT side were $(1.83 \pm 0.54)$ and $(2.04 \pm 0.48)$ respectively. The mean values and SD of distal latency of RT side for groups ( $A$ and $B$ ) after the study were $(4.81 \pm 0.51)$ and $(4.83 \pm 0.49)$ respectively, of LT side were $(4.76 \pm 0.68)$ and $(4.61 \pm 0.602)$ respectively. The mean values and SD of MNCVof RT side for groups ( $A$ and $B$ ) after the study were $(42.9 \pm 1.97)$ and $(43.59 \pm 1.79)$ respectively, of $L T$ side were $(42.7 \pm 3.13)$ and $(42.5 \pm 2.26)$ respectively. There was no significant difference between two groups post-study in pain level where P-values was (0.606). There were no significant differences between two groups in amplitude, distal latency and MNCV of RT side post-study, where P-values were (0.082), (0.911) and (0.342) respectively. There were no significant differences between two groups in amplitude, distal latency and MNCV of LT side post-study, where P-values were $(0.265),(0.550)$ and $(0.334)$ respectively.
Table 3. Post-study mean values of measured variables for both groups.

\begin{tabular}{llllll}
\hline & & $\begin{array}{l}\text { Group A } \\
\text { Mean } \pm \text { SD }\end{array}$ & $\begin{array}{l}\text { Group B } \\
\text { Mean } \pm \text { SD }\end{array}$ & t-value & p-value \\
\hline Pain level & & $2 \pm 0.53$ & $2.1 \pm 0.833$ & -0.521 & 0.606 \\
\hline Amplitude & RT & $1.85 \pm 0.388$ & $2.1 \pm 0.383$ & -1.8 & 0.082 \\
& LT & $1.83 \pm 0.54$ & $2.04 \pm 0.48$ & -1.13 & 0.265 \\
\hline Distal latency & RT & $4.81 \pm 0.51$ & $4.83 \pm 0.49$ & -0.113 & 0.911 \\
& LT & $4.76 \pm 0.68$ & $4.61 \pm 0.602$ & 0.605 & 0.550 \\
\hline MNCV & RT & $42.9 \pm 1.97$ & $43.59 \pm 1.79$ & -0.968 & 0.342 \\
& LT & $42.7 \pm 3.13$ & $42.5 \pm 2.26$ & 0.22 & 0.334 \\
\hline
\end{tabular}

\section{Comparison of pre and post study for group $A$}

As shown in Table 4, the mean values and SD of pain for group A pre and post-study was $(7.8 \pm 0.86)$ and $(2 \pm 0.53)$ respectively. The mean values and SD of amplitude of RT side for group A pre and post-study were $(1.32 \pm 0.278)$ and $(1.85 \pm 0.388)$ respectively and for $\mathrm{LT}$ side were $(1.11 \pm 0.44)$ and $(1.83 \pm 0.54)$ respectively. The mean values and SD of distal latency of RT side for group A pre and post-study were $(6.08 \pm 0.598)$ and $(4.8 \pm 0.51)$ respectively and for $\mathrm{LT}$ side were $(5.87 \pm 0.74)$ and $(4.76 \pm 0.68)$ respectively. The mean values and SD of MNCV of RT side for group A pre and post-study were $(40.68 \pm 2.83)$ and $(42.92 \pm 1.97)$ respectively and for LT side were $(38.5 \pm 4.82)$ and $(42.7 \pm 3.13)$ respectively. There were significant differences between pre and post-study in all measured variables, where P-values were (0.000).

\section{Comparison of pre and post study for group B}

As shown in Table 5, the mean values and SD of pain for group B pre and post-study was (7.66 \pm 1.17$)$ and $(2.1 \pm 0.833)$ respectively. The mean values and SD of amplitude of RT side for group B pre and post-study were $(1.43 \pm 0.286)$ and $(2.1 \pm 0.383)$ respectively and for LT side were $(1.35 \pm 0.48)$ and (2.04 \pm 0.48$)$ respectively. The mean values and SD of distal latency of RT side for group B pre and post-study were $(6.05 \pm 0.68)$ and $(4.83 \pm 0.49)$ respectively and for $\mathrm{LT}$ side were $(5.66 \pm 0.64)$ and $(4.61 \pm 0.602)$ respectively. The mean values and SD of MNCV of RT side for group B pre and post-study were $(41.07 \pm 2.79)$ and $(43.59 \pm 1.79)$ respectively and for LT side were $(39.11 \pm 3.52)$ and $(42.5 \pm 2.26)$ respectively. There were significant differences between pre and post-study in all measured variables, where P-values were $(0.000)$.

\section{Discussion}

Diabetic peripheral neuropathy is the presence of symptoms or signs of peripheral nerve dysfunction in people with diabetes after exclusion of other causes [29]. It represents $60 \%$ of people with diabetes, confers the greatest risk of foot ulceration $[30,31]$. Neuropathy causes loss of protective sensation and loss of co-ordination of muscle groups in the foot and leg that lead to increase mechanical stresses during ambulation [32,33]. 
Mohamed et al. Physical Therapy and Rehabilitation 2017, http://www.hoajonline.com/journals/pdf/2055-2386-4-17.pdf

Table 4. Pre-study post-study mean values of measured variables for group A.

\begin{tabular}{lllllll}
\hline \multicolumn{7}{c}{ Group A } \\
\hline Items & & $\begin{array}{l}\text { Pre-study } \\
\text { Mean } \pm \text { SD }\end{array}$ & $\begin{array}{l}\text { Post-study } \\
\text { Mean } \pm \text { SD }\end{array}$ & \% of change & t-value & p-value \\
\hline Pain level & & $7.8 \pm 0.86$ & $2 \pm 0.53$ & $74.4 \%$ & 29 & 0.000 \\
\hline Amplitude & RT & $1.32 \pm 0.278$ & $1.85 \pm 0.388$ & $40.2 \%$ & -7.78 & 0.000 \\
& LT & $1.11 \pm 0.44$ & $1.83 \pm 0.54$ & $64.8 \%$ & -8.37 & 0.000 \\
\hline Distal latency & RT & $6.08 \pm 0.598$ & $4.8 \pm 0.51$ & $-21 \%$ & 9.26 & 0.000 \\
& LT & $5.87 \pm 0.74$ & $4.76 \pm 0.68$ & $-20.4 \%$ & 5.82 & 0.000 \\
\hline MNCV & RT & $40.68 \pm 2.83$ & $42.92 \pm 1.97$ & $5.5 \%$ & -4.33 & 0.000 \\
& LT & $38.5 \pm 4.82$ & $42.7 \pm 3.13$ & $10.9 \%$ & -0.321 & 0.000 \\
\hline
\end{tabular}

Table 5. Pre-study post-study mean values of measured variables for group $B$.

\begin{tabular}{lllllll}
\hline \multicolumn{7}{c}{ Group B } \\
\hline & & $\begin{array}{l}\text { Pre-study } \\
\text { Mean } \pm \text { SD }\end{array}$ & $\begin{array}{l}\text { Post-study } \\
\text { Mean } \pm \text { SD }\end{array}$ & \% of change & t-value & p-value \\
\hline Pain level & & $7.66 \pm 1.17$ & $2.1 \pm 0.833$ & $-72.6 \%$ & 41.5 & 0.000 \\
\hline Amplitude & RT & $1.43 \pm 0.286$ & $2.1 \pm 0.383$ & $46.9 \%$ & -7.08 & 0.000 \\
& LT & $1.35 \pm 0.48$ & $2.04 \pm 0.48$ & $51.1 \%$ & -7.47 & 0.000 \\
\hline Distal latency & RT & $6.05 \pm 0.68$ & $4.83 \pm 0.49$ & $-20.2 \%$ & 8.56 & 0.000 \\
& LT & $5.66 \pm 0.64$ & $4.61 \pm 0.602$ & $-18.6 \%$ & 5.26 & 0.000 \\
\hline MNCV & RT & $41.07 \pm 2.79$ & $43.59 \pm 1.79$ & $6.1 \%$ & -4.51 & 0.000 \\
& LT & $39.11 \pm 3.52$ & $42.5 \pm 2.26$ & $8.7 \%$ & -5.83 & 0.000 \\
\hline
\end{tabular}

Diabetic peripheral neuropathy is estimated to occur in 50-90\% of individuals with diabetes for more than 10 years [34]. The impairment of peripheral nerve function in diabetic individuals should be regarded not as a neurological complication but as a neurological manifestation of the disease $[35,36]$ It approaches $50 \%$ in most diabetic population, mainly with painful symptoms [37].Treating neuropathy is a difficult task for the physician and most of the conventional pain medications primarily mask symptoms $[38,39]$ and have significant side effects and addiction profiles. So, the aim of our study is evaluating the effects of LLLT versusPEMF on pain intensity and motor nerve conduction velocity (MNCV) in patients with diabetic neuropathy.The present study showed that both PEMF and LLLTimproved amplitude, distal latency and bilateral peronealMNCV. Also, the study results, demonstrating significant pain relief in all patients in both groups. Comparative analysis showed non-significant differences between group $A$ and $B$ after treatment.

The improvement of electrophysiological parameters (peroneal MCV, amplitude and distal latency) in the Laser group could be explained as follows; laser has a biostimulational effect on the nervous system [40]. Earlier research findings suggested that LLL treatment appears to enhance re innervation of target tissues subsequent to nerve injury [41]. Rochkind [42] found that laser improves function recovery and recruitment of voluntary muscle activity through application transcutaneously to the site of nerve injury (15 $\mathrm{min}$ ) and to the corresponding segments of the spinal cord (15 min).
The other studies concluded that laser irradiation prevents motor cell degeneration, induces Schwann cell proliferation, allows higher neural metabolism, and increases myelination and axon regeneration $[\mathbf{1 4}, \mathbf{4 3}]$. NCS is known as the gold standard for diagnosis of neuropathy, and it is correlated with disease severity [44]. In this study, we used NCS in order to objectively evaluate the effect of LLLT in the treatment of distal symmetric diabetic polyneuropathy. The exact mechanism by which LLLT improves NCV is largely unknown. However, several theories may help explain the enhanced conduction velocity observed here. Laser radiation has been shown to change cell and tissue function [45]. It has been suggested that irradiation activates collagen synthesis, varies DNA synthesis [46], improves the function of damaged neurological tissue [47], reduces inflammation, and relieves pain [48].

Despite the previous observations by Zinman et al. [49], and Peric et al. [50], who reported that current results do not provide sufficient evidence to recommend LLLT for pain symptoms in polyneuropathy, this study clearly demonstrated a significant positive effect of LLLT on improvement of nerve conduction velocity on distal symmetric polyneuropathy. In our study, objective criteria based on NCS was positively correlated with the therapeutic potential of LLLT.

Patients receiving LLLT had a decrease of pain level through four weeks of treatment. It was reported that LLLT improve local microcirculation and it can also improve oxygen supply to hypoxic cells and at the same time it can remove the collected waste products [51]. In the cases of neuropathic 
pain, the analgesic effects of LLLT may be due to the local release of neurotransmitters such as serotonin, increased mitochondrial ATP production, increased release of endorphins, or anti-inflammatory effects. The mechanism whereby LLLT relieves pain is unknown [52].

PEMF group showed improved peroneal nerve distal latency and nerve conduction velocity (NCV) that can be attributed to few studies suggested that endoneurial capillaries in peripheral nerves of the diabetes are thickened [53] and perineurial basement membrane are widened [54]. A permeability disorder at the blood nerve or blood perineurial barrier in diabetics could lead to endoneurial metabolic derangements, however possibly resulting in neuropathy. PEMF by targeting at increased circulation and anti-inflammatory effects combined with the pain relief and restoration of normal nerve conduction lead to reversal of the damage that cause the peripheral neuropathy. Recently, it has been observed that PEMF modulates the neurite growth in vitro and nerve regeneration in vivo, which further explains the improvement obtained in results of group $B$.

In the available literature, there is limited research on PEMF treatmentfor diabeticperipheral neuropathy; nevertheless, a few studies support the current findings. In such studies, study of PEMF [55] directed to investigate the effect of PEMF on pain and motor nerve conduction velocity (NCV) in patients with diabetic neuropathy revealed significant reduction of pain intensity and significant improvement of peroneal nerve conduction velocity $(\mathrm{m} / \mathrm{s})$.

Previous studies had reported that PEMFs are able to modify some parameters of nerve function in diabetic patients and can stimulate nerve growth, regeneration, and functional recovery of nerves in cells in animal models with nerve disease [56,57].

The effects of PEMF are to trigger a biologic response such as cell proliferation that represents the basic effect to explain some relevant results. It enhances nerve regeneration and accelerates recovery in experimentally divided and sutured peroneal nerve which can improve number of nerve fiber and thereby amplitude achieved in nerve conduction study [58].

Application of PEMF facilitates regression of the main clinical symptoms of DPN, improves the conductivefunction of peripheral nerves, improves the state of $1 \mathrm{a}$ afferents, and improves the reflex excitability of functionally diverse motor neurons in the spinal cord. This explanation is supported by Musaev et al. [59] who performed a clinical and electro neuromyographic study in 121 patients with diabetic polyneuropathy before and after the courses of treatment with PEMFs at different frequencies $(100$ and $10 \mathrm{~Hz})$. The study concluded that PEMF at $10 \mathrm{~Hz}$ was found to have therapeutic efficacy, especially in the initial stages of DPN and in patients with DM for up to 10 years.

The reduction of pain intensity was better after treatment of PEMF, and this result is in agreement with Morki and Sinaki [60] who postulated that magnetic therapy has become one of the most rapidly emerging alternative therapies where magnets have been promoted for their analgesic and energizing effects with no adverse effects unlike drugs. The analgesic effect of PEMF therapy could be attributed to the physiologic mechanisms of pain relief, which may be owing to presynaptic inhibition or decreased excitability of pain fibers [61].

Moreover, PEMF can modulate the action of hormones, antibodies, and neurotransmitter surface receptor sites of a variety of cell types. This may cause changes in transfer rate of electrons during the electron exchange between single molecules that may either slow down or accelerate chemical reactions [62].

The pain is most likely to arise from increased activity of injured small - diameter regenerating fibers, [63] which fire rapidly and at abnormally low thresholds [64].The PEMF influence diabetic neurons and cell membrane of cutaneous nociceptors thereby inducing change in the cellular [65] and pericellular microenvironment $[66,67]$.

\section{Conclusions}

The study findings indicate that LLLT and PEMF could be an effective therapeutic modality in the treatment of painful diabetic neuropathy in that they are able to modify pain, and some electrophysiological parameters of peripheral nerve function. Further studies would be worthwhile because diabetic neuropathy is a disorder with multiple symptoms which affects function, produces pain, autonomic involvement and future studies can consider functional improvements, pain threshold, Assessing sensory and motor impairment.

\section{Competing interests}

The authors declare that they have no competing interests.

\section{Authors' contributions}

\begin{tabular}{|l|c|c|c|c|}
\hline Authors' contributions & RAM & GAA & HAA & AAN \\
\hline Research concept and design & $\checkmark$ & $\checkmark$ & -- & -- \\
\hline Collection and/or assembly of data & $\checkmark$ & $\checkmark$ & -- & -- \\
\hline Data analysis and interpretation & $\checkmark$ & $\checkmark$ & $\checkmark$ & $\checkmark$ \\
\hline Writing the article & $\checkmark$ & $\checkmark$ & -- & -- \\
\hline Critical revision of the article & $\checkmark$ & $\checkmark$ & $\checkmark$ & $\checkmark$ \\
\hline Final approval of article & $\checkmark$ & $\checkmark$ & $\checkmark$ & $\checkmark$ \\
\hline Statistical analysis & $\checkmark$ & $\checkmark$ & $\checkmark$ & $\checkmark$ \\
\hline
\end{tabular}

\section{Acknowledgements}

Many thanks, to all patients who participated in this study for their co-operation.

\section{Publication history}

Editor: Mohammad H. Hadadzadeh, Wheeling Jesuit University, USA. Received: 12-Oct-2017 Final Revised: 12-Dec-2017

Accepted: 18-Dec-2017 Published: 31-Dec-2017

\section{References}

1. Forbes JM and Cooper ME. Mechanisms of diabetic complications. Physiol Rev. 2013; 93:137-88. | Article | PubMed

2. Young MJ, Veves A, Walker MG and Boulton AJ. Correlations between nerve function and tissue oxygenation in diabetic patients: further clues 
Mohamed et al. Physical Therapy and Rehabilitation 2017,

to the aetiology of diabetic neuropathy? Diabetologia. 1992; 35:114650. | PubMed

3. Barrett AM, Lucero MA, Le T, Robinson RL, Dworkin RH and Chappell AS. Epidemiology, public health burden, and treatment of diabetic peripheral neuropathic pain: a review. Pain Med. 2007; 8 Suppl 2:S5062. | Article | PubMed

4. Tesfaye $S$ and Selvarajah D. Advances in the epidemiology, pathogenesis and management of diabetic peripheral neuropathy. Diabetes Metab Res Rev. 2012; 28 Suppl 1:8-14. | Article | PubMed

5. Weisman A, Bril V, Ngo M, Lovblom LE, Halpern EM, Orszag A and Perkins BA. Identification and prediction of diabetic sensorimotor polyneuropathy using individual and simple combinations of nerve conduction study parameters. PLoS One. 2013; 8:e58783. | Article | PubMed Abstract | PubMed FullText

6. van Deursen RW and Simoneau GG. Foot and ankle sensory neuropathy, proprioception, and postural stability. J Orthop Sports Phys Ther. 1999; 29:718-26. | Article | PubMed

7. Simoneau GG, Derr JA, Ulbrecht JS, Becker MB and Cavanagh PR. Diabetic sensory neuropathy effect on ankle joint movement perception. Arch Phys Med Rehabil. 1996; 77:453-60. | Pdf I PubMed

8. Head KA. Peripheral neuropathy: pathogenic mechanisms and alternative therapies. Altern Med Rev. 2006; 11:294-329. | Pdf | PubMed

9. Davies M, Brophy S, Williams R and Taylor A. The prevalence, severity, and impact of painful diabetic peripheral neuropathy in type 2 diabetes. Diabetes Care. 2006; 29:1518-22. | Article | PubMed

10. Dworkin RH, O'Connor AB, Backonja M, Farrar JT, Finnerup NB, Jensen TS, Kalso EA, Loeser JD, Miaskowski C, Nurmikko TJ, Portenoy RK, Rice AS, Stacey BR, Treede RD, Turk DC and Wallace MS. Pharmacologic management of neuropathic pain: evidence-based recommendations. Pain. 2007; 132:237-51. | Article | PubMed

11. Rochkind $S$ and Ouaknine GE. New trend in neuroscience: low-power laser effect on peripheral and central nervous system (basic science, preclinical and clinical studies). Neurol Res. 1992; 14:2-11. | PubMed

12. Rochkind S. Phototherapy in peripheral nerve regeneration: From basic science to clinical study. Neurosurg Focus. 2009; 26:E8. | Article | PubMed

13. Rochkind S, Nissan M, Razon N, Schwartz M and Bartal A. Electrophysiological effect of HeNe laser on normal and injured sciatic nerve in the rat. Acta Neurochir (Wien). 1986; 83:125-30. | PubMed

14. Barbosa RI, Marcolino AM, de Jesus Guirro RR, Mazzer N, Barbieri CH and de Cassia Registro Fonseca M. Comparative effects of wavelengths of low-power laser in regeneration of sciatic nerve in rats following crushing lesion. Lasers Med Sci. 2010; 25:423-30. | Article | PubMed

15. KazemiKhoo N. Successful treatment of diabetic foot ulcers with lowlevel laser therapy. The Foot. 2006; 16:184-7.

16. Schindl A, Schindl M, Schon $H$, Knobler R, Havelec $L$ and Schindl L. Lowintensity laser irradiation improves skin circulation in patients with diabetic microangiopathy. Diabetes Care. 1998; 21:580-4. | PubMed

17. Schindl A, Heinze G, Schindl M, Pernerstorfer-Schon H and Schindl L. Systemic effects of low-intensity laser irradiation on skin microcirculation in patients with diabetic microangiopathy. Microvasc Res. 2002; 64:240-6. | Article | PubMed

18. Gu" ngo" rmu" s_ M and Akyol UK. Effect of bio stimulation on wound healing in diabetic rats. Photo med Laser Surg. 2009; 27:607-10.

19. Balducci S, Leonetti F, Di Mario U and Fallucca F. Is a long-term aerobic plus resistance training program feasible for and effective on metabolic profiles in type 2 diabetic patients? Diabetes Care. 2004; 27:841-2. | Article | PubMed

20. Kishimoto H, Taniguchi A, Fukushima M, Sakai M, Tokuyama K, Oguma T, Nin K, Nagata I, Hayashi R, Kawano M, Hayashi K, Tsukamoto Y, Okumura T, Nagasaka S, Mizutani $H$ and Nakai Y. Effect of short-term low-intensity exercise on insulin sensitivity, insulin secretion, and glucose and lipid metabolism in non-obese Japanese type 2 diabetic patients. Horm Metab Res. 2002; 34:27-31. | Article | PubMed

21. Musaev AV, Guseinova SG and Imamverdieva SS. The use of pulsed electromagnetic fields with complex modulation in the treatment of patients with diabetic polyneuropathy. Neurosci Behav Physiol. 2003; 33:745-52. | PubMed

22. Graak V, Chaudhary S, Bal BS and Sandhu JS. Evaluation of the efficacy of pulsed electromagnetic field in the management of patients with diabetic polyneuropathy. Int J Diabetes Dev Ctries. 2009; 29:56-61. I Article | PubMed Abstract | PubMed FullText

23. Emanuel $R$ and Faber J.Essert pathology. 2nd ed, Lippincott (Philadelphia). 1995.

24. Asburym $M$ and Thomas."Pathophysiology and root disorder" in diseases of nervous system, 2nd ed. Mosby Co. 1992.

25. Ferraz MB, Quaresma MR, Aquino LR, Atra E, Tugwell P and Goldsmith $\mathrm{CH}$. Reliability of pain scales in the assessment of literate and illiterate patients with rheumatoid arthritis. J Rheumatol. 1990; 17:1022-4. | PubMed

26. Daube JR. Nerve conduction studies. In: Aminoff MJ, editor. Electrodiagnosis in clinical neurology. USA: Churchill Livingstone. 1999.

27. Zinman LH, Ngo M, Ng ET, Nwe KT, Gogov S and Bril V. Low-intensity laser therapy for painful symptoms of diabetic sensorimotor polyneuropathy: a controlled trial. Diabetes Care. 2004; 27:921-4. | Article | PubMed

28. Mirkovic VB, Banjac L, Dasic $Z$ and DapcevicM. Non-pharmacological treatment of diabetic polyneuropathy by pulse electromagnetic field. Healthmed. 2012; 6:1291-1295.

29. Dianna Q and Emad S. Diabetic Neuropathy. Neurology. Neuromuscular Diseases Medicine Specialties. 2006.

30. Boulton AJ, Kirsner RS and Vileikyte L. Clinical practice. Neuropathic diabetic foot ulcers. N Engl J Med. 2004; 351:48-55. | Article | PubMed

31. Holstein PE and Sorensen S. Limb salvage experience in a multidisciplinary diabetic foot unit. Diabetes Care. 1999; 22 Suppl 2:B97-103. | PubMed

32. Bakker K., Foster A.V.M. and Van HoutoumW.H. Time to act. The Netherlands: International Diabetes Federation and International Working Group of the Diabetic Foot, 2005.

33. Papanas N, Maltezos E and Edmonds M. The diabetic foot: a plea for the elementary? Acta Diabetol. 2006; 43:152-3. | Article | PubMed

34. Vinik Al. Diagnosis and management of diabetic neuropathy. Clin Geriatr Med. 1999; 15:293-320. | PubMed

35. Kotov SV, Kalinin AP and RudakovaIG. Diabetic Neuropathy (in Russian) Meditsina. Moscow. 2000.

36. Kotov SV, NeretinVYa, Petina LV and KamyninaTS. Clinical and electroneurophysiological studies of the state of the neuromuscular system in patients with diabetes mellitus types I and II. ZhNevrol Psikhiatr. 1997; 97:34-8.

37. Boulton AJ and Malik RA. Diabetic neuropathy. Med Clin North Am. 1998; 82:909-29. | Article | PubMed

38. Tang J, Wingerchuk DM, Crum BA, Rubin DI and Demaerschalk BM. Alpha-lipoic acid may improve symptomatic diabetic polyneuropathy. Neurologist. 2007; 13:164-7. | Article | PubMed

39. ADA. Standards of medical care in diabetes (position statement). Diabetes Care. 2006; 29:42.

40. Rochkind S and Ouaknine GE. New trend in neuroscience: low-power laser effect on peripheral and central nervous system (basic science, preclinical and clinical studies). Neurol Res. 1992; 14:2-11. | PubMed

41. Anders JJ, Borke RC, Woolery SK and Van de Merwe WP. Low power laser irradiation alters the rate of regeneration of the rat facial nerve. Lasers Surg Med. 1993; 13:72-82. | Article | PubMed

42. Rochkind S. Phototherapy in peripheral nerve regeneration: From basic science to clinical study. Neurosurg Focus. 2009; 26:E8. | Article | PubMed

43. Khullar SM, Brodin P, Messelt EB and Haanaes HR. The effects of low level laser treatment on recovery of nerve conduction and motor function after compression injury in the rat sciatic nerve. Eur J Oral Sci. 1995; 103:299-305. | Article | PubMed

44. Schroder S, Liepert J, Remppis A and Greten JH. Acupuncture treatment improves nerve conduction in peripheral neuropathy. Eur J Neurol. 
Mohamed et al. Physical Therapy and Rehabilitation 2017,

http://www.hoajonline.com/journals/pdf/2055-2386-4-17.pdf

doi: 10.7243/2055-2386-4-17

\section{7; 14:276-81. | Article | PubMed}

45. Hopkins JT,McLoda TA, Seegmiller JG and David Baxter G. Low level laser therapy facilitates superficial wound healing in humans: atriple-blind, sham-controlled study. J Athl Train. 2004; 39:223-229.

46. Oron A, Oron U, Streeter J, de Taboada L, Alexandrovich A, Trembovler $V$ and Shohami E. low-level laser therapy applied transcranially to mice following traumatic brain injury significantly reduces long-term neurological deficits. J Neurotrauma. 2007; 24:651-6. | Article | PubMed

47. Huang YY, Chen AC, Carroll JD and Hamblin MR. Biphasic dose response in low level light therapy. Dose Response. 2009; 7:358-83. | Article | PubMed Abstract I PubMed FullText

48. Zinman LH, Ngo M, Ng ET, Nwe KT, Gogov S and Bril V. Low-intensity laser therapy for painful symptoms of diabetic sensorimotor polyneuropathy: a controlled trial. Diabetes Care. 2004; 27:921-4. | Article | PubMed

49. Perić $Z$ and Cvetković $B$. Electrophysiological evaluation of lowintensity laser therapy in patients with diabetic polyneuropathy. FACTA UNIVERSITATIS Series: Medicine and Biology. 2006; 13:11-14.

50. Baxter D. "Low-intensity laser therapy", In Kitchen, S. and Bazin, S (eds.), Electrotherapy: Evidence-Based practice, 11th ed., Churchull Living Stone, Edinburgh, 2002: 180.

51. Nikolaeva NV, Bolotova NV, Luk'yanov VF, Raigorodskii YM and Tkacheva EN. Non-pharmacological correction of impaired microcirculation in children with diabetic polyneuropathy. Neurosci Behav Physiol. 2010; 40:347-50. | Article | PubMed

52. Fisher MA, Langbein WE, Collins EG, Williams K and Corzine L. Physiological improvement with moderate exercise in type II diabetic neuropathy. Electromyogr Clin Neurophysiol. 2007; 47:23-8. | PubMed

53. Vital C, Brechenmacher C, Cardinaud JP, Manier G, Vital A and Mora $B$. Acute inflammatory demyelinating polyneuropathy in a diabetic patient: predominance of vesicular disruption in myelin sheaths. Acta Neuropathol. 1985; 67:337-40. | PubMed

54. Beggs JL, Johnson PC, Olafsen AG, Watkins CJ, Targovnik JH and Koep LJ. Regression of perineurial cell basement membrane in a human diabetic following isogenic pancreas transplant. Acta Neuropathol. 1989; 79:10812. | PubMed

55. Graak V, Chaudhary S, Bal BS and Sandhu JS. Evaluation of the efficacy of pulsed electromagnetic field in the management of patients with diabetic polyneuropathy. Int J Diabetes Dev Ctries. 2009; 29:56-61. I Article | PubMed Abstract | PubMed FullText

56. Frahm J, Lantow M, Lupke M, Weiss DG and Simko M. Alteration in cellular functions in mouse macrophages after exposure to $50 \mathrm{~Hz}$ magnetic fields. J Cell Biochem. 2006; 99:168-77. | Article | PubMed

57. Kim S, Im WS, Kang L, Lee ST, Chu K and Kim BI. The application of magnets directs the orientation of neurite outgrowth in cultured human neuronal cells. J Neurosci Methods. 2008; 174:91-6. | Article | PubMed

58. Behse F, Buchthal F and Carlsen F. Nerve biopsy and conduction studies in diabetic neuropathy. J Neurol Neurosurg Psychiatry. 1977; 40:107282. | Article | PubMed Abstract | PubMed FullText

59. Musaev AV, Guseinova SG and Imamverdieva SS. The use of pulsed electromagnetic fields with complex modulation in the treatment of patients with diabetic polyneuropathy. Neurosci Behav Physiol. 2003; 33:745-52. | PubMed

60. Morki B and Sinaki M. Painful disorders of the spine and back pain syndromes. In: Sinaki M, editor. Basic clinical rehabilitation medicine. 2nd ed. St. Louis: Mobsy. 1993; 489-502.

61. Arokoski JP, Valta T, Kankaanpaa M and Airaksinen O. Activation of lumbar paraspinal and abdominal muscles during therapeutic exercises in chronic low back pain patients. Arch Phys Med Rehabil. 2004; 85:82332. | Article | PubMed

62. Van Nguyen JP and Marks R. Pulsed electromagnetic fields for treating osteoarthritis. Physiotherapy. 2002; 88:458-470.

63. Eglen RM, Hunter JC and Dray A. Ions in the fire: recent ion-channel research and approaches to pain therapy. Trends Pharmacol Sci. 1999; 20:337-42. | Article | PubMed

20:337-42. I Article I PubMed
64. Brown MJ and Asbury AK. Diabetic neuropathy. Ann Neurol. 1984; 15:212. | Article | PubMed

65. Itegin M, Gunay I, Logoglu $G$ and Isbir T. Effects of static magnetic field on specific adenosine-5' - triphosphatase activities and bioelectrical and biomechanical properties in the rat diaphragm muscle. Bioelectromagnetics. 1995; 16:147-51. | PubMed

66. Zochodne DW. Diabetic Neuropathies. Current Treat options Neurol. 2000; 2:23-9.

67. Zochodne DW. The microenvironment of injured and regenerating peripheral nerves. Muscle Nerve Suppl. 2000; 9:S33-8. | PubMed

\section{Citation:}

Mohamed RA, Abdallah GA, Abdeen HA and Nassifg AA. Influence of low level laser therapy versus pulsed electromagnetic field on diabetic peripheral neuropathy. Phys Ther Rehabil. 2017; 4:17. http://dx.doi.org/10.7243/2055-2386-4-17 